\begin{tabular}{|c|c|c|}
\hline \multirow{4}{*}{$\begin{array}{r}\text { Case Reports in } \\
\text { Gastroenterology }\end{array}$} & \multirow{2}{*}{\multicolumn{2}{|c|}{ Case Rep Gastroenterol 2017;11:645-650 }} \\
\hline & & \\
\hline & $\begin{array}{l}\text { DOl: 10.1159/000480376 } \\
\text { Published online: October 30, } 2017\end{array}$ & $\begin{array}{l}\text { (C) } 2017 \text { The Author(s) } \\
\text { Published by S. Karger AG, Basel } \\
\text { www.karger.com/crg }\end{array}$ \\
\hline & \multicolumn{2}{|c|}{$\begin{array}{l}\text { This article is licensed under the Creative Commons Attribution-NonCommercial } 4.0 \\
\text { International License (CC BY-NC) (http://www.karger.com/Services/OpenAccessLicense) } \\
\text { Usage and distribution for commercial purposes requires written permission. }\end{array}$} \\
\hline
\end{tabular}

\title{
Hepatocyte Nuclear Factor 1 $\alpha$-Mutated Hepatocellular Adenomas: An Atypical Presentation
}

\author{
Camila Maria Neves Sousa $^{a} \quad$ Patricia Maria Miranda Gadelha ${ }^{a}$ \\ Rafaella de Sousa Cartaxo ${ }^{a}$ George Washington Holanda Pedrosa ${ }^{a}$ \\ Rodrigo Schuler Honorio ${ }^{b}$ José Milton de Castro Lima ${ }^{c}$ \\ Gustavo Rêgo Coelho ${ }^{d}$ Clovis Rêgo Coelho ${ }^{a}$ \\ asão Carlos Institute of Education and Research, Farias Brito Faculty, Fortaleza, Brazil; \\ ${ }^{b}$ Hospital Infantil Albert Sabin, Fortaleza, Brazil; ' Department of Clinical Medicine, \\ Faculty of Medicine, Federal University of Ceará, Fortaleza, Brazil; dDepartment of Surgery, \\ Faculty of Medicine, Federal University of Ceará, Fortaleza, Brazil
}

\section{Keywords}

Hepatocellular adenoma $\cdot$ Hepatocyte nuclear factor $1 \alpha \cdot$ Surgical intervention

\begin{abstract}
Hepatocellular adenomas (HCAs) are rare benign monoclonal hepatic tumors that commonly occur in females (3-4 per 100,000 women) due to the use of oral contraceptives, its primary risk factor. Recently, HCAs have been classified into 4 distinct subtypes according to genotypic and phenotypic characteristics and clinical features: inflammatory HCA (40-50\%), which are hypervascular with marked peliosis and a tendency to bleed; hepatocyte nuclear factor $1 \alpha(\mathrm{HNF1A})$-mutated HCA (H-HCA, 30-40\%) that are diffusely steatotic and rarely undergo malignant transformation; $\beta$-catenin activated HCA (10-15\%), which frequently undergo malignant transformation and may seem hepatocellular carcinoma on imaging; and unclassified HCA (10-25\%). In this study, we report the case of a 23-year-old female oral contraceptive user with $\mathrm{H}-\mathrm{HCA}$. Usually, $\mathrm{H}-\mathrm{HCA}$ is considered to be nonsevere in most cases and often requires outpatient follow-up. However, in this case, the injury had substantially increased in volume and evolved with a major bleeding frame, which was an unusual finding for this subtype of adenoma. The therapeutic used for this patient was a laparoscopic left hepatic seg-
\end{abstract}




\section{Case Reports in Gastroenterology}

Case Rep Gastroenterol 2017;11:645-650

\begin{tabular}{l|l}
\hline DOI: $10.1159 / 000480376$ & $\odot 2017$ The Author(s). Published by S. Karger AG, Basel \\
\hline
\end{tabular} www.karger.com/crg

Sousa et al.: Hepatocyte Nuclear Factor $1 \alpha$-Mutated Hepatocellular Adenomas: An Atypical Presentation

mentectomy. Thus, the choice of treatment to be performed in a patient with $\mathrm{H}-\mathrm{HCA}$ can depend on the tumor size $(>5 \mathrm{~cm})$, the outcome of previous bleeding, and the risk of bleeding recurrence.

\section{Background}

Hepatocellular adenomas (HCAs) are rare monoclonal benign liver tumors that most commonly occur in women (3-4 per 100,000 women) [1, 2]. HCAs are the third most prevalent benign tumors of the liver and have the capacity to undergo malignant transformation $[2,3,4]$.

Contraceptive use is an important risk factor for developing HCA, and its risk is determined by the time of use and the amount of estrogen present in the oral contraceptive drug. HCA rarely occurs in children and men (male:female ratio $=1: 9$ ). Other risk factors for HCAs include the use of anabolic steroids, glycogen storage disease (types Ia, III, and VI), hemochromatosis, androgen therapy, and the use of barbiturates and clomiphene [5].

Recently, HCA has been classified into 4 distinct subtypes according to genotypic and phenotypic characteristics and clinical features: inflammatory HCA (IHCA, 40-50\%), hepatocyte nuclear factor $1 \alpha(\mathrm{HNF} 1 \mathrm{~A})$-mutated HCA (H-HCA, 30-40\%), $\beta$-catenin activated HCA (bHCA, 10-15\%), and unclassified HCA (UHCA, 10-25\%) [1, 6, 7]. IHCA is characterized by the presence of serum and lesional indicators (such as higher serum levels of amyloid A and Creactive protein) of an active inflammatory response; it has also been linked to activating mutations in several genes, including IL6ST, FRK, STAT3, JAK1, and GNAS, and is hypervascular with marked peliosis and a tendency to bleed $[6,8,9]$. IHCA is associated with obesity, alcohol use, and hepatic steatosis. Approximately $10 \%$ of the inflammatory subtype can show additional $\beta$-catenin activation and may progress to hepatocellular carcinoma (HCC). H-HCA exhibits inactivating mutations in the HNF1A (TCF1) gene causing loss of hepatocyte nuclear factor $1 \alpha(\mathrm{HNF}-1 \alpha)$ expression and a downregulation of the liver fatty acid-binding protein (LFABP). This subtype is diffusely steatotic, rarely leads to malignant progression, and is associated with familial diabetes or adenomatosis [10]. The subtype b-HCA is related to male hormone administration and glycogen storage disease, typified by activating mutations of $\beta$-catenin that resist phosphorylation-mediated downregulation by the GSKB/APC/ AXIN complex. The result is an accumulation of nuclear $\beta$-catenin which, combined with deletion of APC, stimulates the progression to HCC [7]. The b-HCA subtype also demonstrates a higher risk of malignant transformation in patients with an HCA larger than 4-5 cm $[6,10]$. UHCA is not yet defined by any particular genetic mutation, but is characterized by various histologic criteria that are unusual in the other subtypes; the underlying pathogenesis of this subtype remains unclear [11].

Patients can present with right upper quadrant pain or a palpable mass. However, up to $50 \%$ of patients are asymptomatic. HCAs can be complicated by life-threatening bleeding or undergo malignant transformation necessitating surgical management [12].

The HCA subtypes show variable complication rates. Hemorrhage can occur in 15-20\% of HCAs [13]. Bleeding can be intratumoral, intrahepatic, or extrahepatic. Risk factors for bleeding of HCA include a diameter of $35 \mathrm{~mm}$ or more, visualization of central and peripheral intralesional arteries, location in the left lateral liver, and exophytic growth [14].

Furthermore, 9\% of HCA may transform into HCC with risk factors including male sex, androgen use, large tumors $(>5 \mathrm{~cm})$, and $\beta$-catenin-mutated HCA [15]. 
The subclassification system for HCA helps clinicians to stratify patients according to imaging criteria, expression of associated immunohistochemical markers, or molecular findings. These data may influence the treatment selected [16], since certain subtypes of HCA pose a greater risk of progression to HCC than others. On the other hand, HCAs can arise with atypical characteristics, presenting aspects of more than 1 subtype. Thus, it can require a different therapeutic approach. Herein, we report a case of H-HCA with atypical features, and surgical intervention was necessary.

\section{Case Presentation}

A 23-year-old woman with a past medical history of oral contraceptive use for 10 years and metformin hydrochloride use, including no previous surgery or cases of cancer in the family. The patients presented to our medical department with a 2-week history of discrete unspecific abdominal pain. Previous ultrasonography had exhibited a large nodule in the left liver lobe. Then, magnetic resonance imaging was performed, and we found a large heterogeneous expansive nodular lesion in the left liver lobe, partially exophytic, located at the periphery of segments II/III, measuring around $10.3 \times 6.8 \times 10.7 \mathrm{~cm}$. The nodular lesion was visualized in the contrast medium without "wash-out," noting a significant signal drop in the out-phase sequence, indicating a massive fat component of the lesion (Fig. 1). These findings are strongly indicative of HNF1A adenoma. However, an intralesional blood component was identified, which was characterized by a high spontaneous signal in the T1 fat-sat sequence, with bleeding being extremely uncommon in the subtype described but more commonly associated with IHCA. Her liver function tests, aspartate aminotransferase and alanine transaminase, exhibited no alterations. Other laboratory testing showed a white cell count of $8.1 \times$ $10^{3} / \mu \mathrm{L}$ (normal range 4.4-11.3 $\times 10^{3} / \mu \mathrm{L}$ ), hemoglobin of $13 \mathrm{~g} / \mathrm{dL}$ (normal range 12.3$15.3 \mathrm{~g} / \mathrm{dL}$ ), platelet count of $355 \times 10^{3} / \mu \mathrm{L}$ (normal range $145-445 \times 10^{3} / \mu \mathrm{L}$ ), international normalized ratio (INR) of 1.01 (normal value 1) and C-reactive protein of $0.75 \mathrm{mg} / \mathrm{dL}$ (normal range $<0.8 \mathrm{mg} / \mathrm{dL}$ ). Tumor marker test revealed $\alpha$-fetoprotein of $3 \mathrm{ng} / \mathrm{mL}$ (negative for malignant tumor).

Despite the bleeding, the important lesional fatty component detected on magnetic resonance imaging was extremely suggestive of $\mathrm{H}-\mathrm{HCA}$, a subtype that is generally treated conservatively. However, considering the tumor volume $(>5 \mathrm{~cm})$, the presence of intralesional blood component, and the risk of bleeding recurrence, left hepatic segmentectomy was performed.

The nodule sections showed neoplasia characterized by proliferation of hepatocytes in relatively delicate trabeculae, with slightly enlarged nuclei, without significant atypia, with frequent macrovascular steatosis (around 40\%), as well as areas of hemorrhage and necrosis (Fig. 2). Moderate inflammatory cell infiltrate and HCA measuring $11 \mathrm{~cm}$ on the largest axis were also found. These morphological changes characterized adenoma associated with inactivation of HNF1- $\alpha$, according to the diagnosis prior to surgery.

\section{Discussion}

We presented the case of a young woman with a history of oral contraceptive use who initially presented with discrete symptoms and an ultrasonography result suggestive of a 
liver lesion. It is known that HCA affects mainly women using oral contraceptives [3], in keeping with our patient.

Magnetic resonance imaging findings showed a contrast-enhanced lesion as well as signal loss in the out-phase, which demonstrated an important fat component, and laboratory testing (such as white cell count and C-reactive protein) did not show a positive result for inflammatory conditions. These findings are characteristic of H-HCA. H-HCAs are characterized histologically by marked steatosis and bland hepatocyte cytology $[10,17]$, which is in accordance with the findings in our patient. On the other hand, the other subtypes (IHCA, bHCA, and UHCA) have no fat aspects on lesion composition [3]. It is noteworthy that the presence of intralesional hematoma is unusual in H-HCA.

Most cases of HCAs are treated conservatively without surgical intervention, and patients are advised to avoid oral contraception. The risk of growth and rupture of HCAs during pregnancy has to be underlined, especially in larger HCAs. Tumor progression, suggested by internal bleeding and malignant transformation, necessitates a more aggressive therapeutic approach, with lesions $>5 \mathrm{~cm}$ considered as the primary risk factor [16]. However, serious complications can occur. Notably, hemorrhage is described in up to one-fourth of patients, mainly associated with large $(>5 \mathrm{~cm})$ lesions.

Thus, the presence of intralesional blood material, identified by the high signal seen in the T1 fat-sat sequence, although uncommon for the HNF1A subtype, can be explained by the lesion size and the presence of other risk factors related to bleeding [18]. As for the present case, its location in the left lobe of the liver and its exophytic growth were factors that contributed to this process.

According to the new Bordeaux classification, when an adenoma $>5 \mathrm{~cm}$ of the H-HCA subtype is confirmed by biopsy, as well as in centers with expertise, it can be managed conservatively [19]. However, HCAs $>5 \mathrm{~cm}$ are already indicative of surgical intervention [18]. In addition, the presence of intralesional blood material and the described characteristics of the lesion indicated progression of the tumor and strongly suggested the possibility of further bleeding. Because of this, we performed the surgical resection.

Thus, we demonstrated that atypical cases of H-HCA can occur, as was the case in this study. In the present study, the HCA was classified as H-HCA that exhibited typical characteristics of this subtype. However, it showed blood inside, besides being a large injury. Thus, we performed hepatic segmentectomy for this HCA subtype due to risk of re-bleeding which can lead to other complications.

\section{Statement of Ethics}

The authors have no ethical conflicts to disclose.

\section{Disclosure Statement}

The authors declare no conflict of interest. 


\section{Case Reports in \\ Gastroenterology}

\begin{tabular}{l|l}
\hline Case Rep Gastroenterol 2017:11:645-650 \\
\hline DOI: 10.1159/000480376 & $\begin{array}{l}\text { @ 2017 The Author(s). Published by S. Karger AG, Basel } \\
\text { www.karger.com/crg }\end{array}$ \\
\hline
\end{tabular}

Sousa et al.: Hepatocyte Nuclear Factor $1 \alpha-$ Mutated Hepatocellular Adenomas: An Atypical Presentation

\section{References}

1 Bioulac-Sage P, Balabaud C, Zucman-Rossi J: Focal nodular hyperplasia, hepatocellular adenomas: past, present, future. Gastroenterol Clin Biol 2010;34:355-358.

2 Rebouissou S, Bioulac-Sage P, Zucman-Rossi J: Molecular pathogenesis of focal nodular hyperplasia and hepatocellular adenoma. J Hepatol 2008;48:163-170.

-3 Margolskee E, Bao F, de Gonzalez AK, Moreira RK, Lagana S, Sireci AN, et al: Hepatocellular adenoma classification: a comparative evaluation of immunohistochemistry and targeted mutational analysis. Diagn Pathol 2016;11:27.

4 Shanbhogue A, Shah SN, Zaheer A, Prasad SR, Takahashi N, Vikram R: Hepatocellular adenomas: current update on genetics, taxonomy, and management. J Comput Assist Tomogr 2011;35:159-166.

-5 García Compeán D, Guzmán de la Garza FJ, Muñoz Espinoza LE, Valadez Castillo R, Martínez Flores AM, Fernández BA, et al: Primary liver cancer. Its epidemiological, clinical and biochemical characteristics. Rev Gastroenterol Mex 1994;59:17-22.

6 Bioulac-Sage P, Rebouissou S, Thomas C, Blanc JF, Saric J, Sa Cunha A, et al: Hepatocellular adenoma subtype classification using molecular markers and immunohistochemistry. Hepatology 2007;46:740748.

7 Nault JC, Bioulac-Sage P, Zucman-Rossi J: Hepatocellular benign tumors-from molecular classification to personalized clinical care. Gastroenterology 2013;144:888-902.

-8 Rebouissou S, Amessou M, Couchy G, Poussin K, Imbeaud S, Pilati C, et al: Frequent in-frame somatic deletions activate gp130 in inflammatory hepatocellular tumours. Nature 2009;457:200-204.

-9 Pilati C, Letouzé E, Nault JC, Imbeaud S, Boulai A, Calderaro J, et al: Genomic profiling of hepatocellular adenomas reveals recurrent FRK-activating mutations and the mechanisms of malignant transformation. Cancer Cell 2014;25:428-441.

10 Zucman-Rossi J, Jeannot E, Nhieu JT, Scoazec JY, Guettier C, Rebouissou S, et al: Genotype-phenotype correlation in hepatocellular adenoma: new classification and relationship with HCC. Hepatology 2006;43:515-524.

-11 Blanc JF, Frulio N, Chiche L, Sempoux C, Annet L, Hubert C, et al: Hepatocellular adenoma management: call for shared guidelines and multidisciplinary approach. Clin Res Hepatol Gastroenterol 2015;39:180 187.

-12 Zucman-Rossi J: Genetic alterations in hepatocellular adenomas: recent findings and new challenges. J Hepatol 2004;40:1036-1039.

13 van Aalten SM, de Man RA, IJzermans JN, Terkivatan T: Systematic review of haemorrhage and rupture of hepatocellular adenomas. Br J Surg 2012;99:911-916.

14 Bieze M, Phoa SS, Verheij J, van Lienden KP, van Gulik TM: Risk factors for bleeding in hepatocellular adenoma. Br J Surg 2014;101:847-855.

15 Belghiti J, Cauchy F, Paradis V, Vilgrain V: Diagnosis and management of solid benign liver lesions. Nat Rev Gastroenterol Hepatol 2014;11:737-749.

16 Marrero J, Maluccio MA, McCurdy H, Abou-Alfa GK: Expert perspectives on evidence-based treatment planning for patients with hepatocellular carcinoma. Cancer Control 2014;21(2 suppl):5-16.

17 Bluteau 0, Beaudoin JC, Pasturaud P, Belghiti J, Franco D, Bioulac-Sage P, et al: Specific association between alcohol intake, high grade of differentiation and 4q34-q35 deletions in hepatocellular carcinomas identified by high resolution allelotyping. Oncogene 2002;21:1225-1232.

18 Khanna M, Ramanathan S, Fasih N, Schieda N, Virmani V, McInnes MD: Current updates on the molecular genetics and magnetic resonance imaging of focal nodular hyperplasia and hepatocellular adenoma. Insights Imaging 2015;6:347-362.

19 Sempoux C, Balabaud C, Bioulac-Sage P: Pictures of focal nodular hyperplasia and hepatocellular adenomas. World J Hepatol 2014;6:580-595. 


\section{Case Reports in Gastroenterology}

\begin{tabular}{l|l}
\hline Case Rep Gastroenterol 2017;11:645-650 \\
\hline DOI: 10.1159/000480376 & $\begin{array}{l}\text { ○ 2017 The Author(s). Published by S. Karger AG, Basel } \\
\text { www.karger.com/crg }\end{array}$ \\
\hline
\end{tabular}

Sousa et al.: Hepatocyte Nuclear Factor $1 \alpha-$ Mutated Hepatocellular Adenomas: An Atypical Presentation
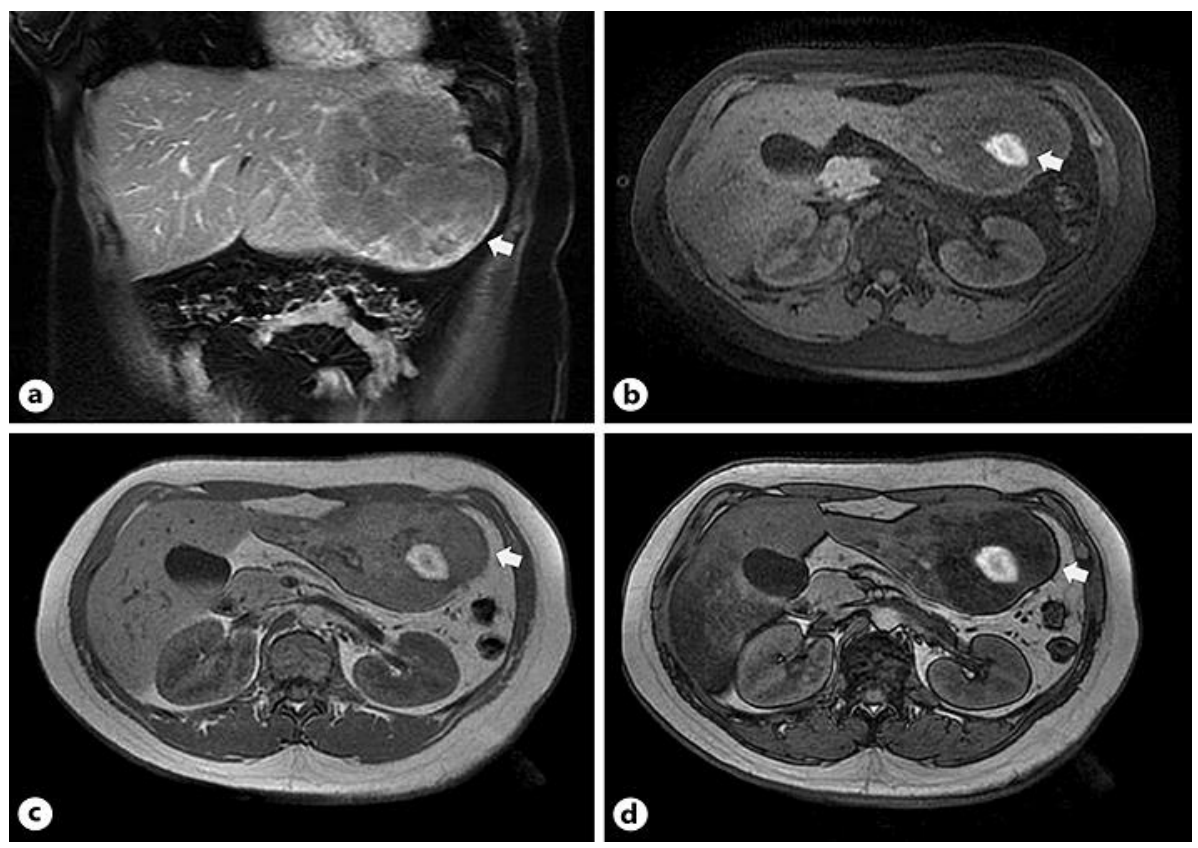

Fig. 1. a Coronal T1 fat-sat with contrast showing a voluminous partial exophytic lesion and heterogeneous aspect in hepatic segments II and III (arrow). b Axial T1 with fat saturation evidencing focus of high signal (arrow) compatible with the blood component inside the lesion. c Axial T1 in-phase showing the lesion in the left lobe with peripheral intermediate signal and central hypersignal area due to the presence of a blood component (arrows). d Axial T1 out-phase showing a significant decrease of the signal of the solid part of the lesion, indicating a predominant adipose composition (arrow).
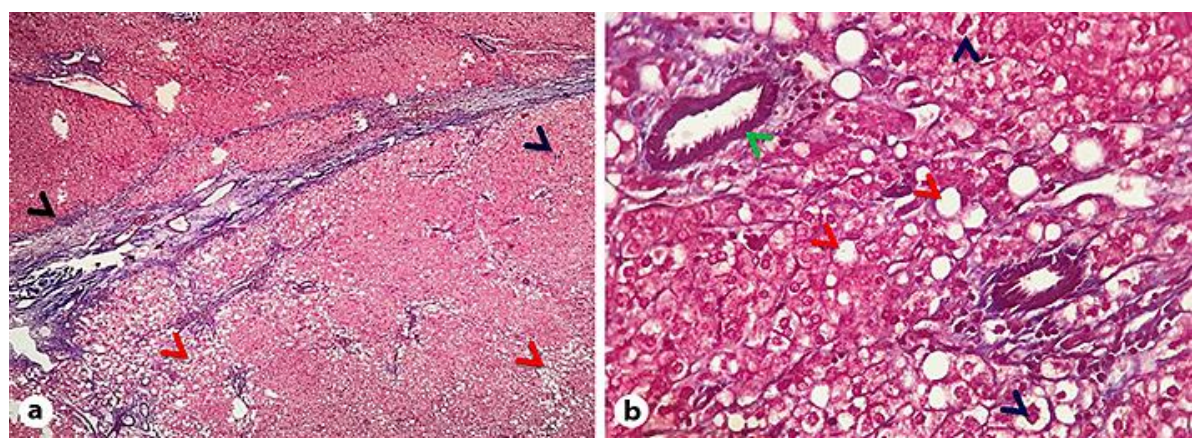

Fig. 2. a Photomicrograph demonstrating the border of the encapsulated nodule (black arrowheads) exhibiting intense hepatocyte proliferation and its parenchyma presenting hepatic steatosis (red arrowheads). b Photomicrograph showing hepatocyte proliferation (blue arrowheads) without significant nuclear atypia, intense formation of hepatic steatosis (red arrowheads), and isolated arterioles (green arrowhead). Masson's trichrome. Magnification $\times 5$ (a) and $\times 100$ (b). 